\title{
Mexican Version of the Epworth Sleepiness Scale
}

\author{
Ulises Jiménez-Correa ${ }^{*},{ }^{1}$, Reyes Haro ${ }^{1}$, Adrián Poblano ${ }^{1}$, Yoaly Arana-Lechuga ${ }^{2}$, Guadalupe \\ Terán-Pérez ${ }^{2}$, Rosa Obdulia González-Robles ${ }^{3}$ and Javier Velázquez-Moctezuma ${ }^{2}$
}

\author{
${ }^{1}$ Clínica de Trastornos del Sueño, Facultad de Medicina, Universidad Nacional Autónoma de México, México \\ ${ }^{2}$ Clínica de Trastornos del Sueño, Universidad Autónoma Metropolitana, Iztapalapa, México \\ ${ }^{3}$ Departamento de Matemáticas, Universidad Autónoma Metropolitana, Iztapalapa, México
}

\begin{abstract}
The Epworth Sleepiness Scale (ESS) has been reputed as a quick, valid, and reliable method to assess Daytime sleepiness (DS). Since its publication, it has been translated into a number of languages. Our aim was to determine validity and reliability indicators of an Spanish language version ESS for Mexican population. Considering that in developing countries the majority of persons use public transportation, validity and reliability indicators were also assessed utilizing the ESS without item 8. ESS was applied to a Group of college students (GCS), a selected group of Healthy subjects (HS), and a Group of patients with Sleep disorders (GPSD). We made an ESS comparison among the 3 groups, calculated the correlation between the ESS and the Multiple Sleep Latency Test (MSLT) and determined construct validity and internal consistency. GCS and GHS had lower ESS scores than GPSD. Regarding convergence validity, we obtained a negative correlation between the ESS and the MSLT; we also found a rise in the ESS score associated with an increase in the Apnea-hypopnea index (AHI). With respect to construct validity (employing main component analysis and varimax rotation), we found that one factor explains $52.01 \%$ of variance. We determined that the ESS internal consistency was 0.85 . When item eight was suppressed, validity and reliability remained acceptable. The present ESS Spanish-language exhibited suitable levels of validity and reliability. Use of the ESS, suppressing item eight, allows assessment of DS more accurately in individuals who do not travel by automobile on a regular basis.
\end{abstract}

Keywords: Diurnal sleepiness, epworth sleepiness scale, multiple sleep latency test, reliability.

\section{INTRODUCTION}

Daytime sleepiness (DS) is one of the main symptoms of sleep disorders [1] and is defined as a tendency to sleep despite the intention to stay awake [2]. It is very important to identify DS, given that it is a symptom related with an increased risk of accidents at home, at work, and on the streets (driving, or as a pedestrian), which cost billions of dollars each year [3]. Also, DS is related with decreased school performance [4] and an increased rate in errors at work [5]. Thus, DS assessment is very important to sleep disorders specialists when making decisions concerning diagnosis and treatment modalities, mainly in patients with an increased risk of DS-associated accidents [6].

There are two electrophysiological tests that assess DS in the sleep laboratory: The Multiple Sleep Latency Test MSLT [7], and the Maintenance of Wakefulness Test (MWT) [8]. These tests are frequently performed at sleep disorder centers, but are expensive and lengthy [2]. Therefore, a rapid and inexpensive way to evaluate DS may be useful, as it would allow for valid and reliable identification of DS. The Epworth Sleepiness Scale (ESS) comprises eight questions that determine DS presence and severity on a scale ranging from of $0-24$ points. The ESS has been translated into a

*Address correspondence to this author at the Clínica de Trastornos del Sueño, Unidad de Medicina Experimental, Hospital General de México, Dr. Balmis 148, Colonia Doctores, C.P. 06726, Distrito Federal, México; Tel: 00152556232690; Fax: 00152556232689; E-mail: ulisesjc@yahoo.com number of languages, such as Spanish [9], German [10], Chinese [11,12], Italian [13], and Greek [14]. Because there are few sleep disorders centers in Mexico, Polysomnography (PSG) and the MSLT are expensive. In addition, there is also a great risk of DS-related accidents in the country. Therefore, it is mandatory to have a Spanish-language version of the ESS designed for Mexican population.

On the other hand, because the majority of persons in developing countries use public transportation to go to workplace, we believe that in countries such as Mexico, there could be a problem in answering ESS question number 8 properly. With these considerations in mind, we determined the validity and reliability of a short ESS version, eliminating item 8 from the test (that reads: in an automobile while stopped for a few minutes in traffic).

\section{MATERIALS AND METHODS}

A group of sleep medicine professionals translated the questions and answer options of the ESS (Fig. 1). In the first stage of this study, the ESS was applied to 694 college students attending the Metropolitan University in Iztapalapa $(43.7 \%$ were male, average age $=22.2$ years \pm 0.13$)$ who were randomly selected. In the second study stage, the ESS was applied, along with a brief sleep symptoms questionnaire, to 250 subjects who accompanied them patients to the School of Medicine's Sleep Disorders Clinic at the National Autonomous University of Mexico (UNAM) in Mexico City. Sixty six (66) subjects from this group were selected for the HS (50\% females, and the remaining 50\% were males, aged 


\section{VERSIÓN MEXICANA DE LA ESCALA DE SOMNOLENCIA EPWORTH UAM-I / UNAM}

Nombre:

Correo electrónico:

Edad: ___ Estatura: ___ Peso: __ Sexo:

INSTRUCCIONES:

Subraye qué tan frecuentemente se queda dormido Ud. e n cada u na de las siguientes situaciones (durante el día) :

1. Sentado leyendo:

$0=$ nunca $\quad 1=$ solo algunas veces $\quad 2=$ muchas veces $\quad 3=$ casi siempre

2. Viendo la televisión:

$0=$ nunca $\quad 1=$ solo algunas veces $\quad 2=$ muchas veces $\quad 3=$ casi siempre

3. Sentado, inactivo en un lugar público:

$0=$ nunca $\quad 1=$ solo algunas veces $\quad 2=$ muchas veces $\quad 3=$ casi siempre

4. Como pasajero en un viaje de una hora (o más) sin paradas:

$0=$ nunca $\quad 1=$ solo algunas veces $\quad 2=$ muchas veces $\quad 3=$ casi siempre

5. Acostado descansando por la tarde:

$0=$ nunca $\quad 1=$ solo algunas veces $\quad 2=$ muchas veces $\quad 3=$ casi siempre

6. Sentado platicando con alguien:

$0=$ nunca $\quad 1=$ solo algunas veces $\quad 2=$ muchas veces $\quad 3=$ casi siempre

7. Sentado cómodamente después de comer, sin haber tomado bebidas alcohólicas:

$0=$ nunca $\quad 1=$ solo algunas veces $\quad 2=$ muchas veces $\quad 3=$ casi siempre

8. Viajando en un transporte detenido en el tráfico:

$0=$ nunca $\quad 1=$ solo algunas veces $\quad 2=$ muchas veces $3=$ casi siempre

Fig. (1). Mexican version of the Epworth Sleepiness Scale (see details in text).

18-70 years) in accordance to the following inclusion criteria: regular schedule for work or school activities (morning/afternoon, but not night shift); subjective nocturnal sleep time at night from 6-9 h, and subjective sleep latency $<20$ min. Subjects with subjective nocturnal awakenings, snoring, who were smokers, central active drug consumption, and chronic illness (mainly psychiatric or neurological diseases) were excluded from this group.

In the third stage of the study, the ESS was applied to 313 subjects from the Group of patients with sleep disorders (GPSD) who underwent a PSG recording at the Sleep disorders clinic of the UNAM School of Medicine, $62.3 \%$ were male, with ages ranged from 18-88 years (subjects from the GPSD had a PSG diagnosis of primary snoring or obstructive sleep apnea or narcolepsy); in 30 of these MSLT was performed as well. PSG and MSLT were conducted according to standard criteria [7, 15]. Diagnosis of a sleep disorder was made in agreement with the International Classification of Sleep Disorders ICSD) [1].
A Spearman test was conducted to assess the correlation between ESS and MSLT. Variance analysis, in addition to a Tukey test, were also performed to compare the ESS score among groups and to compare the ESS score among different levels of sleep apnea syndrome severity (mild, moderate, and severe). Employing these procedures, we determined convergence validity.

Later, utilizing factorial analysis (main component analysis with varimax rotation), we calculated construct validity. Finally, we used a Cronbach alpha test to determine ESS internal consistency. All statistical analyses were carried out using all eight questionnaire items and were then repeated eliminating item number 8 .

\section{RESULTS}

In Table 1, we can observe that on utilizing the complete version of the ESS, the GPSD had more somnolence when compared with the Group of healthy subjects (GHS) and with the Group of college students (GCS) (Anova: $F=66.08$, 
Table 1. ESS Scores for GHS, GCS, and GPSD

\begin{tabular}{|c|c|c|c|c|}
\hline & $\begin{array}{l}\text { Healthy Subjects } \\
\quad n=66\end{array}$ & $\begin{array}{l}\text { College Students } \\
\quad n=694\end{array}$ & $\begin{array}{l}\text { Patients with Sleep Disorders } \\
\qquad n=313\end{array}$ & $+P<$ \\
\hline ESS (mean \pm SEM with eight items & $6.48 \pm 0.35$ & $7.93 \pm 0.13$ & $11.57 \pm 0.41$ & $p<0.001$ \\
\hline ESS (mean \pm SEM) without item 8 & $6.40 \pm 0.36$ & $7.81 \pm 0.13$ & $10.49 \pm 0.4$ & $p<0.001$ \\
\hline
\end{tabular}

GHS $=$ Group of healthy subjects; GCS $=$ Group of college students; GPSD = Group of patients with sleep disorders; SEM $=$ Standard error of mean; $+=$ One way Anova test; $+p$ $<0.05$.

$2-1,070, p<0.001)$. With the short version ESS, significant differences were found among the three groups (Anova: $\mathrm{F}=$ 40.98, 2-1024, $p<0.001)$.

\section{Convergence Validity}

With the complete ESS, we found a negative correlation between the MSLT and the Mexican version of the ESS (rho $=-0.537, p<0.001)$; this correlation was similar using the short- version ESS (rho $=-0.527, p<0.022$ ). An increase in ESS score was also identified as related with sleep apneahypopnea syndrome severity, while the complete version differences were observed between the mild and severe groups as follows: $\mathrm{F}=4.402,2-182, p<0.014$, as was the case with the ESS short version: $\mathrm{F}=4.032,2-184, p<0.02$ (Fig. 2).

\section{Construct Validity}

By analyzing main components and varimax rotation, we determined that the eight ESS items evaluate a general factor (DS), which explains the $52.017 \%$ of total variance. Using the short version of the ESS, we found that the 7 items evaluate a factor that explains $45.971 \%$ of total variance. In both versions, we found that there is only one factor with an eigen value of $>1$. Factorial charge was relatively high in all items.

\section{Reliability}

With the complete version of the ESS, we determined an alpha coefficient $=0.8583$, showing a very acceptable reliability; with the short version, the alpha coefficient was slightly lower, but acceptable (alpha $=0.7273)$.

In the complete version, we found that item number 3 had a greater correlation with the total ESS score (0.736), and item number 6 had the lowest correlation with a total scale score $(0.425)$. In addition, we found that eliminating item number 3 resulted in the greatest decrease in alpha value $(0.8254)$, indicating that this item contributes the most to ESS reliability, while item 6 contributes the least (alpha = 0.8587 ).

With the ESS short version, we again found that item 3 had the best correlation with total ESS score (0.497), while item number 6 had the lowest correlation (0.310). We found that eliminating item 3 produced the highest alpha-value decrease $(0.6815)$, while on the other hand, by eliminating item 6, we found the lowest decrease of alpha (0.7220).

Employing a correlation matrix among items, we found that in the complete ESS version, all items have the same direction (positive). The correlation nearest to zero $(0.067)$ between items 5 and 6 demonstrates that despite that both items were elaborated to evaluate DS, they are virtually in-

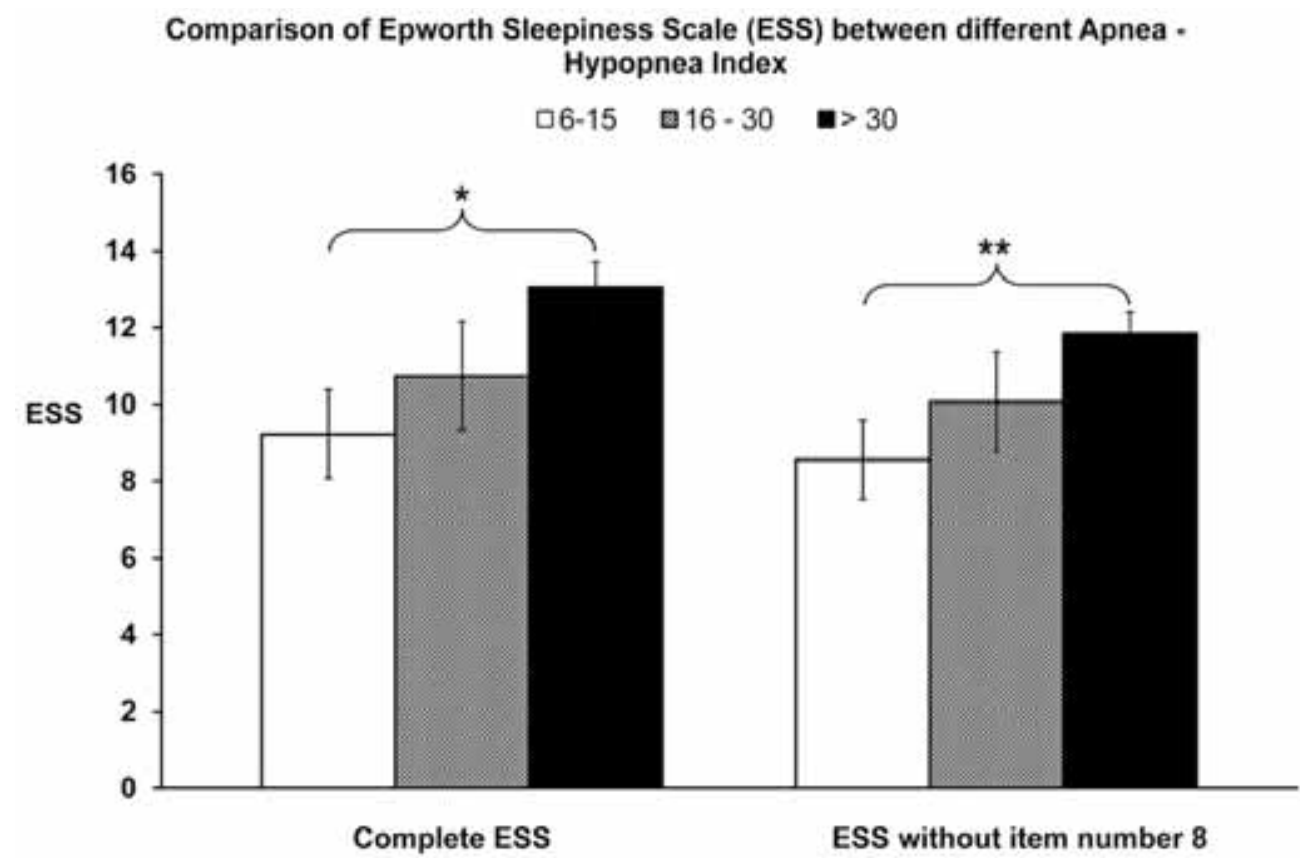

Fig. (2). ESS scores between different sleep apnea/hypopnea severity groups (6-15, 16-30, and >30 events/h of sleep). One-way ANOVA, complete ESS $* p<0.01$, ESS without item number $8 ; * * p<0.02$. 
dependent. Items 3 and 4 had the highest correlation (0.596), indicating that they are the most closely items related within the scale. In the short-version ESS, all correlations again were positive, and we are able to state that all items have the same direction. Once more, item 6 has the lowest correlation with item 5 (0.067), showing that they are virtually independent. In the short-version ESS, there are few correlations $>0.3$, and only one is $>0.4$; nevertheless, all of these showed that the items possess a common relationship, because they were created as indicators for the same variable.

\section{DISCUSSION}

Many limitations have been pointed out in the ESS. Violani [16] reported that ESS sensitivity may be limited when detecting intermediate variations of DS, and the author proposed adding items regarding potentially somnogenic conditions. In addition, the ESS cannot be answered by an illiterate subject without help [17]. Also, it is noteworthy that unlike the Stanford Sleepiness Scale (SSS), the ESS does not assess DS at the time at which the instrument is being answered. Another ESS problem is that it loses a piece of information when it is applied to subjects who do not perform one of the eight activities indicated in the items on a regular basis. For example, in developing countries, the majority of the population does not travel by automobile; thus, there is clear difficulty in obtaining a proper response to item number 8 .

Despite the previously described issues concerning the instrument since its publication in 1991, ESS has been validated in many countries and is widely used as a screening tool for DS in patients with sleep disorders and in patients with comorbidity-associated DS. In this investigation, the ESS (with either 7 or 8 items) allowed us to find differences between healthy subjects and patients with sleep disorders, and both versions also exhibited a significant negative correlation with MSLT. Accordingly, our Mexican (Spanishlanguage) version of the ESS has acceptable characteristics of convergence validity.

Comparing the ESS among sleep apnea hypopnea severity groups, we found a significant difference between the mild and severe groups; these differences can be observed in both versions of the ESS and are indicators of diagnostic validity.

In relation to construct validity, in the complete and short versions of the ESS, factorial analysis indicates that there is a sole factor that integrates the ESS, and according to studies from 1991, this could be diurnal sleepiness (DS) [18].

In terms of complete-version ESS reliability, we found a very acceptable alpha coefficient, while our study showed a lower but acceptable alpha indicator with the short-version ESS. The alpha coefficient allows us to state that both ESS versions possess very good internal consistency. In both versions, item 3 contributed the most to internal consistency, and item 6 contributed the least to ESS reliability.

In both ESS versions, we found that all items have the same direction. Moreover, in both versions we found that items 5 and 6 are virtually independent, inferring that these items assess different characteristics of sleepiness.

Despite the existence of other ESS Spanish-language versions ESS $[9,19]$, the multiplicity of idiomatic regional- isms in countries whose inhabitants speak the Spanish language, generates the need for accurate local language versions to increase reliability.

\section{CONCLUSIONS}

The psychometric properties of the complete and short versions of the ESS permitted us to find differences between healthy subjects and patients with sleep disorders. In addition, both versions demonstrated acceptable indicators regarding validity and reliability. For these reasons, we propose that a short- version ESS should be used, eliminating item 8 , in developing countries in which the majority of the population travels by public transportation.

\section{ACKNOWLEDGEMENTS}

The authors wish to express their gratitude to Maggie Brunner, M.A. and Edith Monroy, for her expert review of the language of the manuscript, and to Marco Elías GudiñoZayas for his support in elaborating the figures. The study was supported in part by CONACyT-México grant \# 119549 (to UJC). This study is part of UJC's doctoral degree in Experimental Biology at the Universidad Autónoma Metropolitana, Iztapalapa (UAM-Iztapalapa).

\section{REFERENCES}

[1] Thorpy MJ. ICSD (International Classification of Sleep Disorders) Diagnostic and coding manual. Diagnostic Classification Steering Committee. Rochester, MN, USA: American Sleep Disorders Association 1990.

[2] Johns MW. A new method for measuring daytime sleepiness: The Epworth sleepiness scale. Sleep 1991; 14: 540-5.

[3] Leger D. The cost of sleep related accidents: a report for the National Commission on Sleep Disorders Research. Sleep 1994; 17: 84-93.

[4] Pallos H, Yamada N, Doi Y, Okawa M. Sleep habits, prevalence and burden of sleep disturbances among Japanese graduate students. Sleep Biol Rhythms 2004; 2: 37-42.

[5] Rogers AE, Wang WT, Scott LD, Aiken LH, Dinges DF. The working hours of hospital staff nurses and patient safety. Health Aff 2004; 23: 203-11.

[6] Stepanski EJ. Controversies in the measurement of daytime sleepiness. Sleep Med Rev 2002; 6: 79-81.

[7] Carskadon MA, Dement WC, Mitler MM, Roth T, Westbrook PR, Keenan S. Guidelines for the multiple sleep latency test (MSLT): A standard measure of sleepiness. Sleep 1986; 9: 519-24.

[8] Mitler MM, Gujavarty KS, Browman CP. Maintenance of wakefulness test: a polysomnographic technique for evaluating treatment in patients with excessive somnolence. Electroencephalogr Clin Neurophysiol 1982; 153: 658-61.

[9] Izquierdo-Vicario Y, Ramos-Platón MJ, Conesa-Peraleja D, Lozano-Parra AB, Espinar-Sierra J. Epworth sleepiness scale in a sample of the Spanish population. Sleep 1997; 20: 676-7.

[10] Bloch KE, Schoch OD, Zhang JN, Russi EW. German version of the Epworth Sleepiness Scale. Respiration 1999; 66: 440-7.

[11] Chung K. Use of the epworth sleepiness scale in Chinese patients with obstructive sleep apnea and normal hospital employees. J Psychosom Res 2000; 49: 367-72.

[12] Chen NH, Johns MW, Li HY, et al. Validation of a Chinese version of the Epworth sleepiness scale. Qual Life Res 2002; 11: 817-21.

[13] Vignatelli L, Plazzi G, Barbato A, et al. Italian version of the Epworth sleepiness scale: external validity. Neurol Sci 2003; 23: 295300 .

[14] Tsara V, Serasli E, Amfilochiou A, Constantinidis T, Christaki P. Greek version of the epworth sleepiness scale. Sleep Breath 2004; 8: 91-5.

[15] Rechtschaffen A, Kales A. A manual of standardized terminology: techniques and scoring system of sleep stages of human subjects. Los Angeles, CA, USA: UCLA Brain Information Service/brain Research Institute; 1968.

[16] Violani C, Lucidi F, Robusto E, Devoto A, Zucconi M, Ferini Strambi L. The assessment of daytime sleep propensity: compari- 
son between the epworth sleepiness scale and a newly development resistance to sleepiness scale. Clin Neurophysiol 2003; 114: 102733

[17] Maldonado CC, Bentley AJ, Mitchell DA. Pictorial sleepiness scale based on cartoon faces. Sleep 2004; 27: 541-8.
[18] Johns MW. Reliability and factor analysis of the epworth sleepiness scales. Sleep 1992; 15: 376-81.

[19] Chica-Urzola HL, Escobar-Córdoba F, Eslava-Schmalbach J. Validación de la Escala de Somnolencia Epworth. Rev Salud Publica 2007; 9: 558-67.

(C) Jiménez-Correa et al.; Licensee Bentham Open.

This is an open access article licensed under the terms of the Creative Commons Attribution Non-Commercial License (http://creativecommons.org/licenses/by-nc/3.0/) which permits unrestricted, non-commercial use, distribution and reproduction in any medium, provided the work is properly cited. 